Authors' own accepted version - may contain typographical errors

Citation:

Allen-Collinson, J, Jennings, G, Vaittinen, A and Owton, H (2019) Weather-wise? Sporting embodiment, weather work and weather learning in running and triathlon, International Review for the Sociology of Sport, 54 (7): 777-792

https://journals.sagepub.com/doi/pdf/10.1177/1012690218761985

\title{
Weather-wise? Sporting embodiment, weather work and weather learning in running and triathlon
}

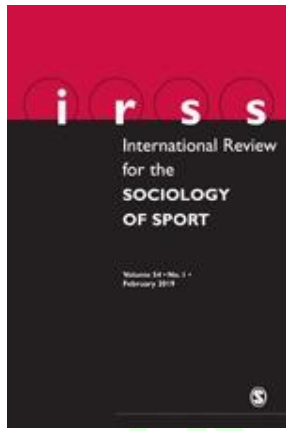

Jacquelyn Allen-Collinson

University of Lincoln, UK

\section{George Jennings}

Cardiff Metropolitan University, UK

Anu Vaittinen

Newcastle University, UK

Helen Owton

The Open University, UK

Email Prof $\mathbf{J}$ Allen-Collinson: jallencollinson@lincoln.ac.uk 


\begin{abstract}
Weather experiences are currently surprisingly under-explored and under-theorised in sociology and sport sociology, despite the importance of weather in both routine, everyday life and in recreational sporting and physical-cultural contexts. To address this lacuna, we examine here the lived experience of weather, including 'weather work' and 'weather learning', in our specific physical-cultural worlds of distance-running, triathlon and jogging in the United Kingdom. Drawing on a theoretical framework of phenomenological sociology, and the findings from five separate auto/ethnographic projects, we explore the 'weather-worlds' and weather work involved in our physicalcultural engagement. In so doing, we address ongoing sport sociological concerns about embodiment and somatic, sensory learning and ways of knowing. We highlight how weather work provides a key example of the phenomenological conceptualisation of the mind-body-world nexus in action, with key findings delineating weather learning across the meteorological seasons that contour our British weather-related training.
\end{abstract}

\title{
Keywords
}

running, somatic learning, sport embodiment, triathlon, weather work 


\title{
Weather-wise?: Sporting embodiment, weather work and weather learning in running and triathlon
}

\begin{abstract}
Weather experiences are currently surprisingly under-explored and under-theorised in sociology and sport sociology, despite the importance of weather in both routine, everyday life and in recreational sporting and physical-cultural contexts. To address this lacuna, here we examine the lived experience of weather, including 'weather work' and 'weather learning', in our specific physical-cultural worlds of distance-running, triathlon and jogging in the United Kingdom (UK). Drawing on a theoretical framework of phenomenological sociology, and the findings from five separate auto/ethnographic projects, we explore the 'weather-worlds' (Ingold, 2010) and weather work involved in our physical-cultural engagement. In so doing, we address ongoing sport sociological concerns with embodiment and somatic, sensory learning and ways of knowing. We highlight how weather work provides a key example of the phenomenological conceptualisation of the mind-body-world nexus in action, with key findings delineating weather learning across the meteorological seasons that contour our British weather-related training.
\end{abstract}

Keywords: somatic learning, sport embodiment, running, triathlon, weather work

\section{Introduction}

Weather experiences are currently under-explored as a key analytic focus in sociology generally and in sport sociology specifically, despite the salient role of weather in sporting and physical-cultural contexts. A game of football in damp autumnal mist, running on a crisp, fresh winter morning, and surfing in the windy, humid heat of the South Pacific are examples taken from our own experiences. Here, drawing on a phenomenological sociological perspective, we 
contribute new theoretical insights to the sociology of sport in relation to embodiment, ${ }^{1}$ social agency and the role of 'embodied learning' (Shilling, 2017) vis-à-vis the lived experience of weather. This is a salient dimension in many sporting and physical-cultural contexts, but one that has received surprisingly scant sociological and/or ethnographic attention (AllenCollinson, 2018; Ingold, 2010). Employing a phenomenologically-inspired form of sociology, we also respond to calls from sociologists of the body to theorise from, rather than merely about, bodies (e.g. Crossley, 2001; Hockey and Allen-Collinson, 2007; Pitts-Taylor, 2015; Wacquant, 2004). In the article, we examine the lived experience of weather, including weather learning, and 'weather work', employing data from five separate auto/ethnographic projects on recreational distance-running, triathlon and jogging, conducted in the UK. In so doing, we address key contemporary sociological concerns with embodiment and somatic learning, and highlight how weather work and weather learning provide salient examples of the phenomenological conceptualisation of the mind-body-world nexus in action. For weather is lived and experienced both corporeally and cognitively, in specific contexts. We also contribute to a relatively small corpus of research on recreational endurance athletes (Groth and Krahn, 2017).

To explore our topic, the article is structured as follows. We first provide some contextualising literature from the small social-scientific literature in which lived experience of weather forms a core focus of analytic attention, before briefly describing our theoretical framework of phenomenological sociology. In order to accord more space to our data, we have not provided detailed discussions of running and triathlon as physical cultures, given that a substantial research literature already exists on these sports/physical cultures (e.g. Atkinson, 2008; Hockey and Allen-Collinson, 2016). We do, however, briefly portray the auto/ethnographic projects from which our data are drawn, and subsequently analyse the key

\footnotetext{
${ }^{1}$ The notion that the body as a material entity is the site and source of cognition, knowledge and experience (see Hopkinson, 2015)
} 
findings in relation to three of the meteorological seasons that strongly contour our British weather-related training.

\section{Lived weather, weather work and phenomenological sociology}

To date, lived weather has remained largely unexplored and untheorised within sociology, despite the significance of weather in our everyday lives (Ingold, 2007, 2010; Ingold and Kurttila 2000; Rantala et al., 2011; Vannini et al., 2012), and also in sporting and physical activity (Allen-Collinson et al., 2017). Whilst there are many studies that include weatherrelated aspects, relatively few consider weather as the central analytic topic. Indeed, as Vannini and colleagues (2012: 363) identify, weather has constituted somewhat of an 'absent-presence' in much social science research, even though the ways in which people experience and talk about weather are sociologically significant and valuable. As these authors highlight, the ways people develop emotional attachments to weather, how they sense and comprehend meteorological processes and imbue them with significance, is of social-scientific interest. Furthermore, Ingold (2010: S122; emphasis in original) argues that 'the experience of weather lies at the root of our moods and motivations'. One exception to this weather-related research lacuna, identified by Rantala and colleagues (2011), is work within tourism studies, which has primarily investigated the impacts of climate change on tourism.

We employ Ingold and Kurttila's (2000: 187) analytically useful distinction between 'climate' as a recorded abstraction compounded from a number of variables such as temperature, precipitation, air pressure, etc. 'Weather', in contrast, is experienced, via feelings of warmth/cold, being drenched by rain, caught in a sudden thunderstorm, and so on, and it is this lived experience that concerns us here. For distance-runners, joggers, and triathletes, whose training predominantly takes place in the outdoors and is therefore subject to all the vagaries of the elements, it is essential to learn how to engage with weather. In our outdoor physicalcultural spaces, we must learn to develop a 'weathering' attitude (Vannini et al., 2012) or 
'weather endurance' (Allen-Collinson, 2018), requiring an active and practical disposition to sense and make sense of, to struggle with and adapt to, weather. This sense of active, reflexive, sometimes mindful and deliberate engagement with the weather is integral to what we term 'weather work' (Allen-Collinson, 2018). We also note, however, that our weather-engagements may be more pre-reflective, 'felt' and sensed, without the weather forming a specific focus of intentionality and conscious reflection. These modes of being-with-weather often shift and change over the course of a run, cycle or swim. Our findings revealed the ways in which, via sensory weather learning and weather work, all the authors grew to develop a 'feel for' weather conditions and their impact upon sporting embodiment and performance. As Ingold and Kurttila (2000) argue, knowledge of weather is not a 'thing', inscribed as a set of prescriptions or formulae, but rather it develops through experience of living and moving in the environment; in our case, our training and racing spaces. One of the theoretical (and methodological) frameworks we have employed in investigating these lived-body experiences is phenomenology, and more specifically phenomenological sociology.

\section{Phenomenologically-attuned sociology}

Modern phenomenology was developed by Edmund Husserl (1900/1901; 2001), who sought a philosophical approach to questioning and challenging everyday ways of thinking and also scientific 'habits of thought' that left unproblematised taken for granted assumptions regarding phenomena. Husserl proposed the phenomenological method as a means of challenging this everyday 'natural attitude', and cutting through layers of sedimented, taken-for-granted assumptions and understandings enveloping phenomena. In brief, central to his method was the phenomenological epoche, often termed 'bracketing', where researchers seek to 'stand aside' from the phenomenon under study, in order to question prior assumptions, and then 'reduce' the phenomenon to its eidos, or core 'essence' (Allen-Collinson, 2011). For us as sociologists, however, any notion that we are able to stand completely outside our own social- 
structural, socio-cultural location is highly problematic; we can make only best efforts to undertake bracketing, as is explained below.

Of key interest to us, however, is Husserl's notion of the Lebenswelt: the commonsense lifeworld of our everyday beliefs, meanings and sense-making; a world intersubjectively coconstructed with others in social interaction. Gros (2017) argues that Schütz (1967) was one of the phenomenologists who contributed most to reflecting on the application of insights from phenomenological philosophy to empirical social sciences. It is to this form of 'sociologized', empirical phenomenology (Allen-Collinson, 2009; Crossley, 2001) that we turn for investigating lived experiences of weather in sporting embodiment. We also employ insights from existentialist phenomenology, including the work of Merleau-Ponty (2001), which highlights the salient role of our own body (le corps propre) or 'body-subject' in our being-inthe-world. For phenomenologists, mind and body are fundamentally intertwined, and mind/body/world are tightly braided. Furthermore, in problematising any clear-cut distinction between body-and-world, Merleau-Ponty's (1969) notion of the 'flesh-of the-world' (la chair) is insightful in analysing how weather phenomena can intermingle with our bodies. Out running on a November night, for example, we might inhale and ingest water droplets hanging in heavy mist, incorporating them into the 'flesh' of our bodies. Similarly, an awareness of danger may be 'felt' inwardly, at a deeply visceral level. Analogously, Howes' (2005, cited in Pink, 2011: 344) notion of emplacement proposes the 'sensuous interrelationship of bodymind-environment'. Such experiences of co-mingling can be difficult to analyse cognitively and represent textually. Reflection, reflexivity and analysis were, however, requisite in our auto/ethnographic projects.

\section{The research}

In common with Ravn and Christensen (2014), we consider phenomenology to involve a specific type of reflection, requiring fundamental and sustained challenging of the tacit, the 
taken-for-granted, and a willingness to question and bracket as far as sociologically possible existing assumptions regarding a phenomenon. Adopting the phenomenological attitude is thus characterised by an openness and unceasingly questioning spirit. Maintaining this attitude requires sustained work, particularly in undertaking the epoche (see for example, AllenCollinson, 2011) vis-à-vis practices with which we are familiar. This is what we sought to do, whilst acknowledging fully that this can only ever produce best efforts at bracketing, within five research projects, which incorporated both autoethnographic and autophenomenographic elements. Whilst autoethnography is now well-known and accepted within the sociology of sport (e.g. Allen-Collinson, 2012; Allen-Collinson et al., 2016; Humberstone, 2011; Nash, 2017; Sparkes, 2000), autophenomenography may be less familiar. This automethodological approach draws on phenomenological principles such as epochē and reduction to identify and explore core structures or patterns of a researcher's own experiences of phenomena (see AllenCollinson, 2009, 2011, for further details). For example, in the collaborative autoethnographic running project, the co-researchers engaged in what Spiegelberg (1975) terms 'cooperative' phenomenology, which involved the bracketing practice of using a reflective log to examine the research process itself, to challenge and question our prior assumptions, preconceptions and tacit knowledge and to discuss our divergent perceptions and experiences of distancerunning embodiment.

For our five projects, we each maintained our own individual training diaries/and or training logs (for further information, see Allen-Collinson et al., 2016) as recreational athletes, which included detailed, reflexive field journals and general field-notes, together with voicerecorded notes. These methods were employed in order to collect data as near to 'real-time' experience as possible. Voice recordings were transcribed as soon as practicable after recording. Data analysis was primarily undertaken via a combination of thematic and phenomenologically-inspired analysis, drawing on Giorgi and Giorgi's (2003) empiricalphenomenological guidelines, including: the adoption of the phenomenological attitude, 
impressionistic readings of data to gain an overall 'feel' for emergent themes, and subsequent closer re-reading and data-immersion, to identify key themes and sub-themes. Following this, extracts and sub/themes were shared between research team-members, and emerging thematic categories and ideas were discussed in detail (see also Allen-Collinson et al., 2016). Employing autoethnographic/autophenomenographic data in this way addresses Garfinkel's (2002: 175) phenomenologically-derived 'unique adequacy requirement' for the researcher to 'be vulgarly competent to the local production and reflexively natural accountability of the phenomenon or order he (sic) is "studying"' (italics in original). We were thus 'vulgarly competent' at 'doing' running, jogging and triathlon and our data were firmly grounded in lived experience.

Jacquelyn is a white-British woman in her late-50s, who commenced off-road distancerunning in her mid-20s and has sometimes engaged in fell and wild running ${ }^{2}$. The findings portrayed derive from two research projects: a collaborative auto/ethnography ${ }^{3}$ and an autophenomenographic study of gender and distance-running.

George is a white-British, middle-class man, aged 33, primarily a martial-artist, for whom jogging supplements martial-arts training. As a running-novice, he kept a diary relating to outdoor jogging sessions of 45-60 minutes.

Anu is a 34-year old woman, a Finnish native now residing in the UK, a martial artist and a novice age-group triathlete. Her triathlon journey began in 2015, a year after anterior cruciate ligament (ACL) reconstruction following a mixed martial arts (MMA) injury. Fieldnotes have been recorded throughout her triathlon training.

Helen is a 38-year old, white-British, middle-class woman, a recreational martial-artist who has competed in karate, boxing, triathlons, and wild running. Her data derive from an

\footnotetext{
${ }^{2}$ Wild running takes place off-road, in wilder, more 'natural' countryside settings such as mountains and moorland, in all seasons, weather, and times of day/night.

3 For the collaborative autoethnography, the co-runner/co-researcher has kindly given permission for data to be included here.
} 
auto/ethnographic study as a boxer and a training diary as a wild-runner. Anu and Helen both suffer from Raynaud's phenomenon, a condition affecting the body's extremities, rendering them particularly susceptible to cold.

\section{Findings and analytic discussion}

From the individual and combined analyses, a raft of themes emerged, some of which are explored elsewhere (Allen-Collinson et al., 2016). It is upon experiences of 'lived weather' that we concentrate here, structured into three seasons of our (UK) meteorological year: winter, spring and autumn. ${ }^{4}$ This is not to say, however, that the British weather fits neatly into clearcut, distinctive seasons, for much of our weather work is generated by the very unpredictability and intermingling of both weather and seasons. Living these seasons, with their myriad weather forms, requires engaging with a gamut of elements and conditions: leaf-littered, swirling autumn gales, cutting, ice-edged winter winds, stinging hail and pelting rain through to gentle, fragrant April showers. Reflecting Merleau-Ponty's (2001) portrayal of the intertwining of body-and-world, our bodies are fundamentally linked to the elemental world as a central structure of our physical-cultural experiences; we must learn how to contend with all its aspects, and engage in weather work in order to train (and race) effectively, and (as far as possible) avoid incurring injury.

\section{The winter's tale}

Ingold (2010) notes that we all have to contend with the weather, even residents of hypermodern cities with air-conditioned, temperature-regulated, glass-enclosed buildings. As academics, we work in environments that include stuffy offices and airless rooms, so escape to the outdoors often represents an enticing prospect, even in inclement conditions. For Jacquelyn,

\footnotetext{
${ }^{4}$ As we have focused upon the summer in earlier work, here we address other seasons.
} 
as a distance-runner who undertakes the majority of her training cross-country, one of the challenges of facing winter weather, particularly cold, frost-laden air, is effectively warming her body (often cramped from long hours of sedentary work) in preparation for running.

The physical and cognitive transition from sitting for extended periods, focused on highconcentration 'head-work', to the demanding 'body-work' of distance-running, can require considerable mind-body adjustment. Failure to warm up effectively in the work-to-run transition did, however, result in somatic learning that muscles can 'pull' and knees 'give way', requiring the sacrifice of precious training-time to 'injury-time'. The dire corporeal consequences of not undertaking weather work in anticipating the effects of cold air on unprepared muscles soon became apparent. Despite the relative boredom of 'warm-up time', Jacquelyn therefore learnt to prepare her body for encountering the winter weather-world. For the most part, a slow, jogging start to the run suffices, but if the weather is particularly cold, then indoor, pre-run stretching may be required:

We've started doing our pre-run stretches on the yoga mats on the balcony overlooking the [University's] swimming pool. The warm, moist air of the pool space is brilliant for warming up, particularly when we've been confined to a desk or lecture theatre for most of the day. By the time we hit the frosty grass on the moon-lit campus this evening, we were so thoroughly warmed up with glow-orange cores that we didn't even notice the cold. By the time we'd registered that it was well below zero, and about 20 mins in, the pool warmth was replaced by our own run-generated inner glow. (Jacquelyn)

In contrast, Helen, a wild-runner with Raynaud's, records that in the midst of running she doesn't feel the cold as much as after the event, when she experiences a 'thrownness' of excessive shivering that makes her whole body shake uncontrollably. During winter, she 
endures high levels of temperature-related discomfort. The winter cold is so deleterious that she even contemplates abandoning winter events, to avoid having to engage in such intense weather work:

When I did the 'Winter Wolf', I wondered how on earth did I get through that freezing cold water and carry on running? Running through rivers, submersing my head in ice cold water, as I carry on running up country hills. But that's wild running... I enjoyed it! It was the freezing aftermath that ruined it all. Whilst I was moving my body coped, and I didn't notice the coldness, I just got through it... Once I stopped, it's like my body shuts down or perhaps it's in shock from what I've put it through. I experienced such excessive and uncontrollable shaking in my body that took over an hour to calm down and warm up. The coldness exacerbated by the wetness is severe and threatening, and puts me off doing other events in the winter. Perhaps it gets worse with age, or I become less tolerant. (Helen)

George prepares for his cold-weather jogging by using exercises previously learned in various fighting systems, involving: stance training, stepping, and exaggerated movements that stress many of the muscles also used in running. Here, he describes his typical warm-up, inspired by the martial art of Xilam (Jennings, 2016):

I stand shoeless, in order to feel the ground beneath me... I bend my knees into the depth of my fighting stance, hold my back straight... I am ready for the 'warrior' walk. The back leg circles into the ankle, and circles out to form the lead leg... I move forwards at different angles, concentrating on one inner thigh gently slapping against the other, and feeling the muscular warmth with this brief contact. I then lower in my stance, and bring my knees higher, focusing on my hip flexors and the 
effort to sustain this across several metres of floor space. Then, I drop down even further, and march with my bent arms swinging in the 'mountain' walk. Finally, I sneak around the flat on the balls of my foot, pulling one arm back as I press the knee up. My calves start to burn slightly, and I know I'm now ready to go outside and face the elements. (George)

Weather learning, a key component of weather work, involves experiential learning about the ways in which meteorological conditions affect the 'going' under foot; as Ingold (2010: S121) notes, we walk at once in the air and on the ground, and our 'knowledge is formed along paths of movement in the weather-world'. British winters are not particularly harsh, cold or snowy in comparison with other less temperate regions of the world, and outside of upland areas, snowfalls are relatively infrequent. Many lowland runners do not, therefore, go to the expense of purchasing specialist trainers for snowy conditions. Anu's weather learning in Finland equipped her well for running in slush, ice and snow, where she learnt how to adjust her gait and balance at every step. Similarly, Jacquelyn recounts running in 'snow-slushy', muddy conditions in the south-west of England, after unusually long-lasting snowfalls followed by heavy rain. Having run for many years in the colder climes of her native northern England, she draws upon prior weather learning to recall the treacherous combination of thawing snow and mud. Sensory feedback from slippery surface and sliding footfall combine with cognition and 'body memories' (Samudra, 2008) as part of her weather work:

Cold wet run tonight as heavy sleet, snow and rain made for a drenching cocktail. A week's snow has been washed into slurry by the heavy rain, making for that strange double-layered surface when newly thawed snow mixes with mud and shifts and slides atop of still frozen ground - treacherous to run on, even though welcome after the compacted ice-packed pavements... Slip-sliding over the sodden grass, I opt for 
the firmness of the rough track through the river meadows as the January night descends. Sleets pelts my frozen cheeks so I pull my ski mask higher, but it's already drenched with the big wet flakes of sodden snow. I seem to be breathing in slushy snow particles... Picking my way carefully around potholes and puddles, I leap straight into an unseen one - cursing, then a moment's anticipation before the near freezing water seeps into my trainers and through two layers of socks... (Jacquelyn)

Reverberating with Ingold's (2010: S121) observation that we walk in the air, in addition to sensory learning vis-à-vis ground, runners often become highly attuned to air (AllenCollinson and Owton, 2014) and the ways in which qualities of air impact upon respiration and thus running. Commensurate with Merleau-Ponty's (1969) portrayal of the melding of mindbody-world, and how we open ourselves up to the world via sensory media, the following data extract from Jacquelyn's log reflects such incorporation of weather and air into body, along with the interconnectedness of ground and body:

Strong zonal run tonight. The compacted ice and snow of recent days washed away by heavy rain and the cutting Easterly wind has given way to an almost balmy Westerly. The air glides into my lungs, smooth, warmed, no residue of the icy shards that provoked coughing and spluttering only days ago. Windy out along the exposed fields but the air seems to part for my body as I wend a steady, rhythmic path down to the weir. The going is perfect, track still slightly dampened, soft from the snow, cushioning my football and bouncing me back for the next stride, as if generating energy from mine and returning it. (Jacquelyn) 


\section{Rites of spring}

The weather and seasonal worlds in which we dwell (Ingold, 2010) place significant demands on the body in water, even when this body has the protection of a wetsuit, trapping a thin layer of water between skin and neoprene suit, creating a kind of a thermal layer to help maintain warmth. Anu uses a wet suit for outdoor swimming, even in the UK summer. Primarily due to low water temperatures, her training is undertaken indoors for practical reasons. Some triathletes and communities of outdoor swimmers do, however, sustain outdoor swimming throughout the year. In terms of weather work, Anu has learnt that in all but the warmest summer weather, she must undergo a process of gradual elemental immersion to 'acclimatize' corporeally to the aquatic environment (see also Throsby, 2013), particularly in spring and autumn:

As soon as my toes touch the water, I feel how cold it is, step by step I wade in, with each step immersing myself in the North Sea a little more. At first the wetsuit provides a comforting barrier, but as I get waist deep I know I have to take the leap in order to acclimatise. It's shallow enough still so I bend my knees so that I am now up to my neck in water, I pull on the collar of the suit to let the water in; jeez it's freezing! To adjust to the water temp, I then pop my goggles in place and drop down to immerse my head a few times over, until the skin on my face and my whole body feels more accustomed to the water temperature. Then I start warming up, swimming short stretches back and forth, kicking my legs a bit stronger to generate a bit more heat to get me ready for the swim. (Anu) 
George, a novice jogger/runner, is still learning how to prepare effectively for running outdoors. His weather learning includes a readjustment to his native British climate (after years spent in Mexico). Here, he portrays finding himself over-dressed for the ever-changeable spring weather after undertaking his first run in many years:

Today marked a new turn in my training. The reintegration of running into my regime. I am wearing the very same kit that I normally use for my Sunday Wing Chun sessions - the zip top covering a long t-shirt and tracksuit bottoms... Glancing down, I see sweat patches on my elbow joints, chest ... and also detected it in the small of my back. Now, writing these notes, different itches emerge on my right collarbone, right shoulder blade and lower stomach region... I yearn for a shower, but know it is important to get these thoughts onto paper. (George)

The need for weather work vis-à-vis clothing choice and adaptation to changeable spring weather is also portrayed by Helen, who, as a runner suffering from Raynaud's, needs to engage in ongoing and active 'temperature work' (Allen-Collinson et al., 2016) both pre- and post-run:

Another post-run chill today. Despite putting extra layers on, wondering if I might overheat, I didn't. I was just right and I can't even remember thinking about my hands on the run today. I just ran. I felt nice and snug. Time whizzed by and I just focused on my running time, my technique and my breathing. Although, even my breathing wasn't in my immediate consciousness while I was running... It was only afterwards, when I was stretching, when I felt my body starting to cool down and shiver from chatting too long. My toes went numb the other day when I was getting gait tested for new trainers and despite the numbness, it hurts. It's when I forget, when I forget to pay attention to the coldness, to my body temperature that 
it hits me out of nowhere - I really need to be more careful. I was relieved to get in a warm, toasty bath and soak my muscles in the soft blanketed water. (Helen)

Similarly, George recalls the need to prepare for the highly changeable conditions often encountered during the British spring. Here, using his prior weather learning, he is cognizant that despite warm sunshine and strengthening sun rays, all can change abruptly to a sudden burst of rain:

The sun is shining outside, and I even see a young man sporting shorts, T-shirt and shades. Despite these bright signs of a sunny day and the estimated forecast of a dry day on my iPhone, I decide to bundle my light raincoat into the midsection of my backpack. I open my sunglasses case and also apply sun protection on my face, next, hands and forearms. If the weather 'holds up', I could train martial arts in the open air in the park. If not, the rain would go away in a few hours anyway, and I could enjoy a run in the park. After an hour of brilliant sunshine, a sudden rainstorm erupts that takes me by surprise. I am in awe of the power of the rain, and I can't imagine walking straightaway, especially in the light New Balance running shoes that were prone to frontal saturation. (George)

This initial weather encounter led George to be somewhat cautious during the springtime weather. As a core element of his weather work, he was gradually learning how to 'read' the weather, the terrain, and how to select appropriate clothing, according to fluctuating levels of warmth. The ambiguity and 'indexicality' of weather and skyscape are highlighted in his data extract: 
The sky is ambiguous. It could be very wet or we could escape a rainstorm. I opted to wear our waterproof coats over our running gear, but once I reach the edge of the lake some 20 minutes into our run, this began to be uncomfortable. I slowly zip my coat down to stomach level, and then took advantage of a steep slope and change in path (the centre of the park was closed by then) to take it off and wrap it around my waist. (George)

Even very experienced runners can be 'caught out' by mercurial springtime conditions. Despite Jacquelyn's decades of running-time, she recounts here finding her choice of running kit woefully inadequate for swiftly dropping temperatures one April evening:

As I set off in the last rays of April sunshine, down the hill towards the playing fields and river, I see a dark, lowering cloud obscures the hills on the other side of the valley. Drat, it looks as though it's going to bucket down or snow heavily. Sure enough the temperature is dropping rapidly and an icy wind's edge chills my skin, which starts to rub against my thin cotton t-shirt. Shall I head home for warmer gear ??... No, but best divert away from the open fields and head towards the scant cover of early spring trees. (Jacquelyn)

Here, weather work includes efforts to 'read the skies' and also to acknowledge the need abruptly to change route if impending weather change is suspected.

\section{Autumn falls}

Autumn (fall) in the UK is a liminal temporal-space between the longer days, light and warmth of summer and the gradual reduction in daylight, temperatures, and increase in rainfall leading to winter. In this section, we focus upon triathlon as a sport where weather work is essential in 
all three of its disciplines: swimming/cycling/running. At its core, triathlon is about sensory attunement, and enskillment (Harris, 2007; Ingold, 2010), learning to sense one's own body temperature in relation to the temperature of the outside weather-world (Ingold, 2010). Most importantly, it is about tuning in, and constantly negotiating how body-world intertwine, harmonise or clash - sometimes in highly varied ways within one single training session or race. Furthermore, during competition and combined-discipline training sessions (e.g. bike-torun elements) weather work can be very different for each discipline. As a triathlete, whether recreational, age-grouper or elite performer, one must become 'weather-wise' and develop weather-work skills, including undertaking temperature work. Such skills are just as refined as the physical conditioning and technical skills required in each of the disciplines.

Failure to acclimatize and adjust gradually to water temperature not only generates bodily discomfort, but can also hinder performance. Anu has learnt that in cooler, autumnal weather, entering cold water too near the race start, not giving her body chance to adjust, can cause muscles to spasm in reaction to the cold; a substantial drop in temperature can literally take her breath away:

The swim takes place in a man-made reservoir, which is both deep and very cold at 7 am on a late September morning, we are ushered into the lake much later than I would like. I try to acclimatise but I can feel the cold is making my muscles spasm. The fog horn signalling start of the race goes off, from treading water I put my head down, all I can see is the black water of the reservoir. One, two, three - breathe, NO! It's not happening I gulp in some lake water as my ribcage simply refuses to expand, I try again. After a few failed attempts I stop for a moment and take breast strokes until I can feel my breathing return to normal and I can get into my rhythm. (Anu) 
The corporeal consequences of failure to engage in weather work, including refined 'temperature work' (Allen-Collinson et al., 2016) in physical-cultural environments, can indeed be severe. Our ability to thermoregulate is vital to our very survival, and immersion in cold water too rapidly or for too long is considered a contributor in the development of lifethreatening conditions such as swimming-induced pulmonary oedema (SIPE) (Smith et al., 2015).

As Vannini et al. (2012) note, experiences of weather and temperature are embodied, not only in the sense that changes in the environment may affect body and health, but also that transformation of the body, for instance through disease, can make a person more sensitive to and perceptive of the environment. During the daily grind of triathlon training, Anu frequently experiences symptoms of Raynaud's phenomenon. This strongly shapes her negotiations of weather work, particularly during autumn where milder weather spells often give way to sudden cold spells accompanied by rain. In the autumn, visible indications of weather conditions (for example, bright sunshine early in the morning) can sometimes suggest that temperatures are higher than they actually are, and this can make contending with Raynaud's phenomenon particularly challenging. Conflating bright autumnal sunshine with actual warmth, without taking into account the wind direction (northern and eastern winds bring low temperatures in the north-east of England) and the wind-chill factor when out cycling at speed, can prove corporeally problematic:

Long Sunday cycle to the coast and back on a bright, late October day, the sun is out, but as I am about half way through the out leg of the ride, I realise how piercing the northern wind is. The cold seems to be getting into my bones despite the layers I have put on. Today keeping my fingers and toes warm on the bike is a real struggle, despite employing my usual tactics to prevent them going white and numb. Instead of gripping the handle bars firmly, I try to loosen 
my grip and wiggle my fingers on the flat sections of the route back. I have light gloves on but the wind seems to be piercing through them, perhaps I should have opted for my light winter bike gloves to keep warm but it seemed a bit too warm for that when I headed out earlier. I've got a similar routine for my toes which equally struggle to deal with the cold, each foot in turn I curl the toes, wiggle them, anything really to prevent them going white and numb from the cold. (Anu)

Cycling, travelling at higher speeds than when running, involves more rapid exposure to the weather, with heat dissipating quickly. Consequently, being soaked by autumn rain and then exposed to wind chill on the bike can provoke rapid cooling. In contrast, when out for a run in the rain, the body heat generated by the action of running means that corporeal cooling is not quite so speedy. Every morning, as part of her weather work, Anu opens the back door of the house to gauge and 'feel' the temperature and weather, carefully surveying the clouds and colour of the sky to assess the likelihood of rain. In the autumn months, the question often centres on whether rain will be a passing shower or whether the heavy grey skies indicate more sustained rainfall.

These then were our lived-weather experiences structured into three seasons, derived from key themes emerging from our automethodological data.

\section{Discussion and conclusion}

For all of us, training outdoors in the mercurial British weather, and being enmeshed in the weather-world are key elements of our sporting embodiment, but ones that to date are very under-researched in the sociology of sport. This is a surprising omission when we consider how many sports - and forms of training for these sports - are so heavily influenced by weather conditions. From the humidity levels affecting the flight of a cricket ball to the wind speeds 
required for yacht racing, weather often lies at the heart of sports engagement. Whilst we may on occasion lament the particular weather conditions and seek to protect ourselves from extremes of weather, there are also elemental pleasures of 'intense embodiment' (AllenCollinson and Owton, 2015). For all the authors, as recreational athletes, there is something sensorially invigorating about immersion in the immediacy and unpredictability of the weatherworld, providing a stark contrast to the often stuffy and airless offices where the majority of our academic working-life takes place. Our sporting life-worlds require that we become 'weather-wise' and also learn to develop 'weather endurance' (Allen-Collinson, 2018; AllenCollinson et al., 2017), as part of our weather work, requiring an active and practical disposition to contend with and adapt to weather. As Moore (2017: 135) portrays in relation to cyclists' weather encounters, these can re/connect us with the environment, and also with the past:

The cold reconnects us with the world our forebears knew, and restores some of the resilience and self-reliance that our warm houses, heated cars and insulated clothing take away. And as it hardens us, so the heat re-forges and tempers us.

Our data also highlight how the lived-experience of weather often involves its active re/production by us as social actors interpreting, making sense of and sometimes communicating 'lived weather' in social interaction; in short, our weather work. For, as Shilling (2018) notes, experience arises from the ongoing interactive flow of individuals engaging with the environment in which they live, and is also manifest through their comments, exclamations, questions, reactions, and changes in expression and posture. Thus, weather work can involve social interactional work as we discuss our lived-weather experiences with others; experiences that are fundamentally shaped by the socio-cultural, social-structural, and physical-cultural domains we inhabit. The norms and values of our 
sporting worlds influence our attitudes towards, and experiences of weather. These physical cultures also contour how - and indeed if - we make manifest and communicate to others our weather experiences. For example, in distance-running where 'doing endurance' (including weather endurance) is highly valorized within the community (Hockey and Allen-Collinson, 2016), 'moaning' about intense cold or heavy rain would breach distance-runners' normative social order. Weather work is thus highly socially mediated, as are lived-weather experiences. Future research might, therefore, examine the specifics of different cultural and physicalcultural influences on the lived experience of weather and weather work.

Automethodological research has, as with all research approaches, certain limitations with regard to traditional, (post)positivist notions of generalizabiltity. As Smith (2018) notes, however, whilst qualitative research may not seek statistical-probabilistic generalizability, it often meets other robust forms of generalizability, such as naturalistic, and analytical generalizability. We seek resonance with readers' experiences in other cognate sporting lifeworlds, thus displaying 'naturalistic generalizability' and transferability (Smith, 2018) to other physical-cultural domains. We also seek to address the criterion of 'analytic generalizability' highlighted by qualitative researchers (e.g. Smith, 2018) via the concept of weather work, as generalizable not only to other sporting environments, but also more widely to human-weather encounters.

The concept of weather work provides a salient exemplar of the cognitive-corporeal nexus at work in sporting embodiment. Shilling (2017), for example, has called for sociology to address as important topics the processes of embodied learning, the acquisition of culturallystructured practices (including sporting practices), and the significance of bodywork and the senses in these processes (Allen-Collinson and Owton, 2015). Shilling (2017) highlights the lack of sociological recognition of the embodied importance of cognition to the incorporation of culture, emphasizing the need for sociological research to consider thought and reflexivity together with the corporeal. Weather work, we argue, involves precisely this cognitive- 
corporeal-cultural nexus, for whilst some of our attunement to weather may be lived at a prereflective, 'gut-feeling' level, much of it is deliberative and reflective, requiring active decision-making.

In this article, we address contemporary sociological debates regarding the need to theorise the inter-relatedness of body, mind, and environment (Shilling, 2017), and also to theorise from, as well as about, lived bodies. Only on the basis of this form of theorising, as Williams and Bendelow (1998) argued some time ago, can an embodied sociology have any real hope of putting minds back into bodies, bodies back into society and society back into the body. Relatedly, we seek to respond to Shilling's (2017) call for sociology to address the embodied importance of cognition to the incorporation of culture. Here, we have analysed some of the practices and modes of undertaking weather work and developing forms of weather wisdom. Our conceptualisation of weather work also coheres with sociologically-attuned conceptualisations of the social production of the senses and the sensory (e.g., Allen-Collinson and Hockey, 2015; Allen-Collinson et al., 2016; Chau, 2008), in that as social actors we must undertake work in sensory production as well as in sensory interpretation. Thus, weather work involves not only considerable interpretative work, but also production work.

\section{References}

Allen-Collinson J (2009) Sporting embodiment: Sports studies and the (continuing) promise of phenomenology. Qualitative Research in Sport and Exercise 1(3): 279-296.

Allen-Collinson J (2011) Intention and epochē in tension: Autophenomenography, bracketing and a novel approach to researching sporting embodiment. Qualitative Research in Sport, Exercise \& Health 3(1): 48-62.

Allen-Collinson J (2012) Autoethnography: Situating personal sporting narratives in sociocultural contexts. In Young K and Atkinson M (eds), Qualitative Research on Sport and Physical Culture. Bingley, UK: Emerald, 191-212.

Allen-Collinson, J (2018) 'Weather work': Embodiment and weather learning in a national outdoor exercise programme. Qualitative Research in Sport, Exercise and Health 10(1): 6374. 
Allen-Collinson $\mathbf{J}$ and Hockey $\mathbf{J}$ (2015) From a certain point of view: Sensory phenomenological envisionings of running space and place. Journal of Contemporary Ethnography 44(1): 63-83.

Allen-Collinson J and Owton H (2014) Take a deep breath: Asthma, sporting embodiment, the senses, and 'auditory work'. International Review for the Sociology of Sport 49(5): 592608.

Allen-Collinson J and Owton H (2015) Intense embodiment: Senses of heat in women's running and boxing. Body \& Society 21(2): 254-268.

Allen-Collinson J, Crust L and Swann C (2017) 'Endurance work': Embodiment and the mindbody nexus in the physical culture of high-altitude mountaineering. Sociology, online early at: http://journals.sagepub.com/doi/10.1177/0038038517746050

Allen-Collinson J, Vaittinen A, Jennings G and Owton H (2016) Exploring lived heat, 'temperature work' and embodiment: Novel auto/ethnographic insights from physical cultures. Journal of Contemporary Ethnography. Epub ahead of print. Available at: http://journals.sagepub.com/doi/pdf/10.1177/0891241616680721

Atkinson M (2008) Triathlon, suffering and exciting significance. Leisure Studies 27(2): 165180.

Chau AY (2008) The sensorial production of the social. Ethnos 73(4): 485-504.

Crossley N (2001) The phenomenological habitus and its construction. Theory and Society 30(1): 81-120.

Garfinkel H (2002). Ethnomethodology's Program: Working out Durkheim's Aphorism. New York: Rowman \& Littlefield.

Giorgi AP and Giorgi BM (2003) The descriptive phenomenological psychological method. In: Camic P, Rhodes JE and Yardley L (eds) Qualitative Research in Psychology. Washington: American Psychological Association, 242-273.

Gros AE (2017) Alfred Schütz on phenomenological psychology and transcendental phenomenology. Journal of Phenomenological Psychology 48 (2): 214-239.

Groth S and Krahn Y (2017) Sensing athletes: Sensory dimensions of recreational endurance sports. Journal of Ethnology and Folkloristics 11(2): 3-23.

Harris M (2007) Introduction: 'Ways of knowing'. In: Harris M (ed), Ways of Knowing: Anthropological approaches to crafting experience and knowledge. New York: Berghahn Books, 1-16.

Hopkinson L (2015) Descartes' shadow: Boxing and the fear of mind-body dualism. HAU: Journal of Ethnographic Theory 5(2): 177-199.

Hockey J and Allen-Collinson J (2007) Grasping the phenomenology of sporting bodies. International Review for the Sociology of Sport 42(2): 115-131 
Hockey J and Allen-Collinson J (2016) Digging in: The sociological phenomenology of 'doing endurance' in distance-running. In Bridel W, Markula P and Denison J (eds), Endurance Running: A Socio-Cultural examination. London: Routledge, 227-242.

Howes D (2005) Introduction. In: Howes D (ed), Empire of the senses: The sensory culture reader. Oxford: Berg, 1-17.

Humberstone B (2011) Embodiment and social and environmental action in nature-based sport: Spiritual spaces. Leisure Studies 30(4): 495-512.

Husserl E (1900/1901; 2001) The Shorter Logical Investigations, Volume 1. London and New York: Routledge. Originally published 1900/1901 in German as Logische Untersuchungen.

Ingold T (2007) Earth, sky, wind, and weather. Journal of the Royal Anthropological Institute $(N S)$ : S19-S38.

Ingold T (2010) Footprints through the weather-world: walking, breathing, knowing. Journal of the Royal Anthropological Institute (N.S.): S121-S139.

Ingold T and Kurttila (2000) Perceiving the environment in Finnish Lapland. Body \& Society 6(3-4): 183-196.

Jennings G (2016) Ancient wisdom, modern warriors: The (re)invention of a Mesoamerican tradition in Xilam. Martial Arts Studies 2: 59-70.

Merleau-Ponty M (1969) The Visible and the Invisible, trans. Lingis A. Evanston, IL: Northwestern University Press.

Merleau-Ponty M (2001) Phenomenology of Perception, trans. Smith C. London: Routledge \& Kegan Paul.

Moore N (2017) Mindful Thoughts for Cyclists: Finding balance on two wheels. Brighton: Leaping Hare Press.

Nash M (2017) Gender on the ropes: An autoethnographic account of boxing in Tasmania, Australia. International Review for the Sociology of Sport 52 (6): 734-750.

Pink S (2011) From embodiment to emplacement: Re-thinking competing bodies, senses and spatialities. Sport, Education and Society 16(3): 343-355.

Pitts-Taylor V (2015) A feminist carnal sociology?: Embodiment in sociology, feminism, and naturalized philosophy. Qualitative Sociology 38: 19-25.

Ravn S and Christensen MK (2014) Listening to the body? How phenomenological insights can be used to explore a golfer's experience of the physicality of her body. Qualitative Research in Sport, Exercise \& Health 6(4): 462-477

Rantala O, Valtonen A and Markuksela V (2011) Materializing tourist weather: Ethnography on weather-wise wilderness guiding practices. Journal of Material Culture 16(3): 285300 . 
Samudra JK (2008) Memory in our body: Thick participation and the translation of kinaesthetic experience. American Ethnologist 35(4): 665-681.

Schütz A (1967) Phenomenology of the Social World, translated by G Walsh and F Lehnert. Evanston, Ill: Northwestern University Press.

Shilling C (2017) Body pedagogics: Embodiment, cognition and cultural transmission. Sociology 51(6): 1205-1221.

Shilling C (2018) Embodying culture: Body pedagogics, situated encounters and empirical research. The Sociological Review 66(1) 75-90.

Smith B (2018) Generalizability in qualitative research: misunderstandings, opportunities and recommendations for the sport and exercise sciences. Qualitative Research in Sport, Exercise and Health 10(1): 137-149.

Smith R, Kerss J and Brooke D (2015) Swimming induced pulmonary oedema - raising awareness about this potentially life-threatening condition. BJSM Blog Series: Sport and Exercise Medicine: the UK trainee perspective. BJSM. Available at: http://blogs.bmj.com/bjsm/2015/05/05/swimming-induced-pulmonary-oedema-raisingawareness-about-this-potentially-life-threatening-condition/ (accessed 1 November 2017).

Sparkes AC (2000) Autoethnography and narratives of self: Reflections on criteria in action. Sociology of Sport Journal 17(1): 21-43.

Spiegelberg H (1975) Doing phenomenology. Essays on and in phenomenology. The Hague: Martinus Nijhoff.

Throsby K (2013) 'If I go in like a cranky sea lion, I come out like a smiling dolphin': Marathon swimming and the unexpected pleasures of being a body in water. Feminist Review 103: $5-22$.

Vannini P, Waskul D, Gottschalk S and Ellis-Newstead T (2012) Making sense of the weather: Dwelling and weathering on Canada's Rain Coast. Space and Culture 15(4): 361-380.

Wacquant L (2004) Body and Soul: Notebooks of an Apprentice Boxer. Oxford: Oxford University Press.

Williams S and Bendelow G (1998) The Lived Body: Sociological Themes, Embodied Issues. London: Routledge. 